\title{
Utilización de alimentos no tradicionales y subproductos agrícolas en la nutrición animal
}

\section{J. Selva Andina Anim. Sci. 2017; 4(1):1-2.}

La producción ganadera del Ecuador está mejorando en los últimos años, gracias a factores como a la incorporación de especies vegetales no tradicionales en la alimentación, así como también del aprovechamiento de subproductos agrícolas, sin embargo, en la actualidad los rumiantes son los mayores contaminantes del planeta, acelerando la destrucción de los ecosistemas, el desarrollo de fenómenos sociales, económicos que afectan al sector productivo pecuario, a los seres humanos en general. Ante esta realidad una disyuntiva técnica, es la formulación de dietas alimenticias alternativas y viables tendientes a disminuir la producción de metano, conjuntamente reducir las pérdidas energéticas en los animales, esta opción se presenta con mayores posibilidades en las condiciones de trópico, la mayoría de los sistemas de producción ganadera tienen reducidos rendimientos debido a la utilización de dietas no balanceadas.

Con seguridad en los posteriores años del presente siglo, habrá un incremento en la demanda de alimentos de origen animal, como resultado del crecimiento demográfico de la población, procesos de culturización, cambios en los hábitos y costumbres en la alimentación. En respuesta a estos requerimientos, la producción animal, específicamente la de rumiantes están experimentado la necesidad de implementar nuevos y mejores sistemas de alimentación y manejo técnico ganadero como una estrategia que permitan acrecentar la producción, abaratar costos, incrementar la disponibilidad de alimento, satisfacer demanda de los consumidores, aumentar los niveles de consumo, contribuyendo de esta manera a la seguridad alimentaria.

El aprovechamiento de especies vegetales no tradicionales y de residuos agroindustriales en ganadería ha sido limitado, sin embargo, procesos investigativos demuestran muchas potencialidades como suplementos nutricionales, alternativa para reducir el impacto ambiental. Igualmente se debe mencionar que la utilización de compuestos conocidos como metabolitos secundarios, que no son sino sustancias químicamente muy diversas, durante mucho tiempo han sido ignorados en los trabajos de nutrición, pero, su carácter claramente ventajoso para las plantas y, en muchos casos para los animales, actualmente han visto en la necesidad de valorar su importancia en la producción agro ganadera, especialmente en aquellos sistemas basados en el aprovechamiento de pastos por su alto contenido de compuestos secundarios. Por otro lado, los aditivos en la alimentación animal son muy diversos y cumplen funciones específicas, cuyo objetivo fundamental es el de 


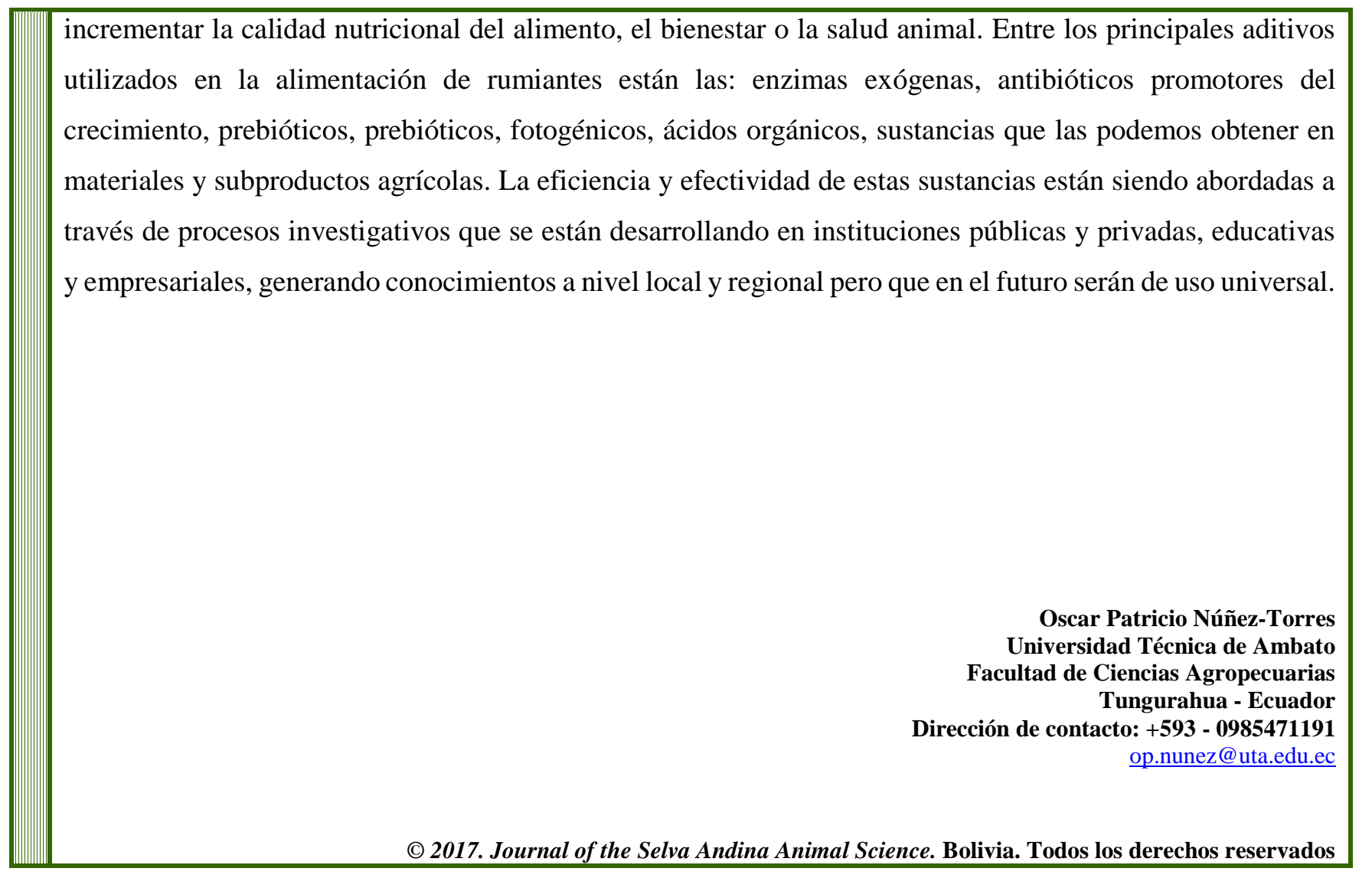

